\title{
Assessment of Mesotrione Leaching Applied Alone and Mixed in Seven Tropical Soils Columns under Laboratory Conditions
}

\author{
Kassio F. Mendes ${ }^{1, *}$ (D), Marcelo R. dos Reis ${ }^{2}$, Kurt A. Spokas ${ }^{3}$ (D) and Valdemar L. Tornisielo ${ }^{1}$ \\ 1 Center of Nuclear Energy in Agriculture, University of São Paulo, Piracicaba, SP 13400-970, Brazil; \\ vltornis@cena.usp.br \\ 2 Institute of Crop Science, Federal University of Viçosa, Rio Paranaíba, MG 38810-000, Brazil; \\ reisagro@gmail.com \\ 3 USDA-Agricultural Research Service, Midwest Area, Saint Paul, MN 55108, USA; kurt.spokas@ars.usda.gov \\ * Correspondence: kassio_mendes_06@hotmail.com; Tel.: +55-19-9-9959-0906
}

Received: 6 October 2017; Accepted: 15 December 2017; Published: 21 December 2017

\begin{abstract}
Herbicide leaching is influenced by soil physical and chemical properties as well as the prevailing climatic conditions. However, little is known about leaching of mixture of herbicides in the soil, especially in tropical regions like Brazil. The objective of this study is to evaluate the leaching of ${ }^{14} \mathrm{C}$-mesotrione (cyclohexane-2- ${ }^{14} \mathrm{C}$-mesotrione) alone and in a mixture with S-metolachlor and terbuthylazine in seven tropical soil columns under laboratory conditions. These soils represented a wide range of properties with varying textures, cation exchange capacity (44 to $\left.154 \mathrm{mmol}_{\mathrm{c}} \mathrm{kg}^{-1}\right), \mathrm{pH}$ (6.0 to 7.7), organic carbon content $\left(0.58\right.$ to $27.32 \mathrm{~g} \mathrm{~kg}^{-1}$ ) and clay mineral contents (50 to $605 \mathrm{~g} \mathrm{~kg}^{-1}$ ), which are typical of tropical soils. Mesotrione residues were observed across all soil column layers $(0-30 \mathrm{~cm})$ in all evaluated soils by simulating $200 \mathrm{~mm}$ of water for $48 \mathrm{~h}$. The application of mesotrione, alone or in a mixture, does not influence the leaching of this herbicide. Leaching of mesotrione ranged from low (up $15 \mathrm{~cm}$ ) to very high (up $30 \mathrm{~cm}$ and leachate) in the tropical soils and may pose a potential groundwater contamination risk. In sand and loamy sand soil, the mesotrione was quantified in the leachate at all sampling times as above $80 \%$ of the amount initially applied. Thus, mesotrione application without the prior knowledge of the soil physical and chemical properties can result in inefficient weed control on field condition due to high leaching potentials.
\end{abstract}

Keywords: weak acid; soil behavior; downward movement; physical and chemical properties; radiolabeled technique

\section{Introduction}

Regardless of the application mode (alone or in a mixture), herbicides will eventually reach the soil. Thus, it is necessary to identify and understand herbicide-soil interactions as influenced by soil physical and chemical properties. Herbicide movement in the soil system occurs in all directions and it is dependent on the direction and rate of water infiltration and flow. Leaching is the name given to the downward movement of the herbicide into the groundwater [1,2].

Mesotrione, belonging to the family of triketones and pigment inhibitors, was one of the first agricultural herbicides to replace atrazine and thereby quickly became widely used by farmers for weed control [3]. In addition, mesotrione is effective at controlling weeds resistant to other herbicides (e.g., ALS-acetolactate synthase enzyme inhibitors and triazines). Mesotrione is generally applied in a mixture with other herbicides, such as S-metolachlor and terbuthylazine [4,5]. However, mixtures of herbicides can alter sorption as well as microbial degradation rates, which lead to alterations in the 
rates of leaching [6]. This behavior help explaining observations of mesotrione in surface water and groundwater [7-10].

Mesotrione sorption is positively correlated with the soil organic carbon content (OC) and inversely correlated with the soil $\mathrm{pH}$ [11]. This correlation can be attributed to herbicide is a weak acid $[\mathrm{pKa}=3.1]$. These two parameters make mesotrione more available for transport by leaching and less bioavailable in the soil solution for microbiological degradation [11-13].

Leaching of the commercial product Lumax ${ }^{\circledR}$, composed of mesotrione, S-metolachlor and terbuthylazine was evaluated in soil from Italy $[4,5]$. However, the potential interactions between herbicides when compared with the application of each herbicide alone were not fully investigated. Many interactions are possible, including those related to changes in the amount and species diversity of the microbial population from different soils, effects on the specific enzymatic reactions, or those related to physical and chemical effects, such as competition for sorption sites, which interfere directly with leaching $[14,15]$.

Thus, the objective of this study is to evaluate the leaching of mesotrione alone and in a mixture with S-metolachlor and terbuthylazine in seven tropical soil types under laboratory conditions.

\section{Materials and Methods}

\subsection{Soil Samples}

Tropical soil samples were collected from the surface layer $(0-10 \mathrm{~cm}$ depth), after removing the vegetated layer, from areas cultivated with corn in Brazil. All soils had not been treated with the mesotrione, S-metolachlor and terbuthylazine for the past 2 years. The soil samples were air-dried for 7 day and then sieved through a $2.0 \mathrm{~mm}$ mesh and stored at room temperature until use ( 1 month). Soil samples were sterilized by gamma irradiation ( $30 \mathrm{kGy}$ ) to inhibit microbial activity for potential degradation during the leaching experiments [12]. The physical and chemical properties of the samples and classification of soils are shown in Table 1. 
Table 1. Physical and chemical properties of tropical soils $(0-10 \mathrm{~cm}$ of depth) cultivated with corn in Brazil studied in this experiment.

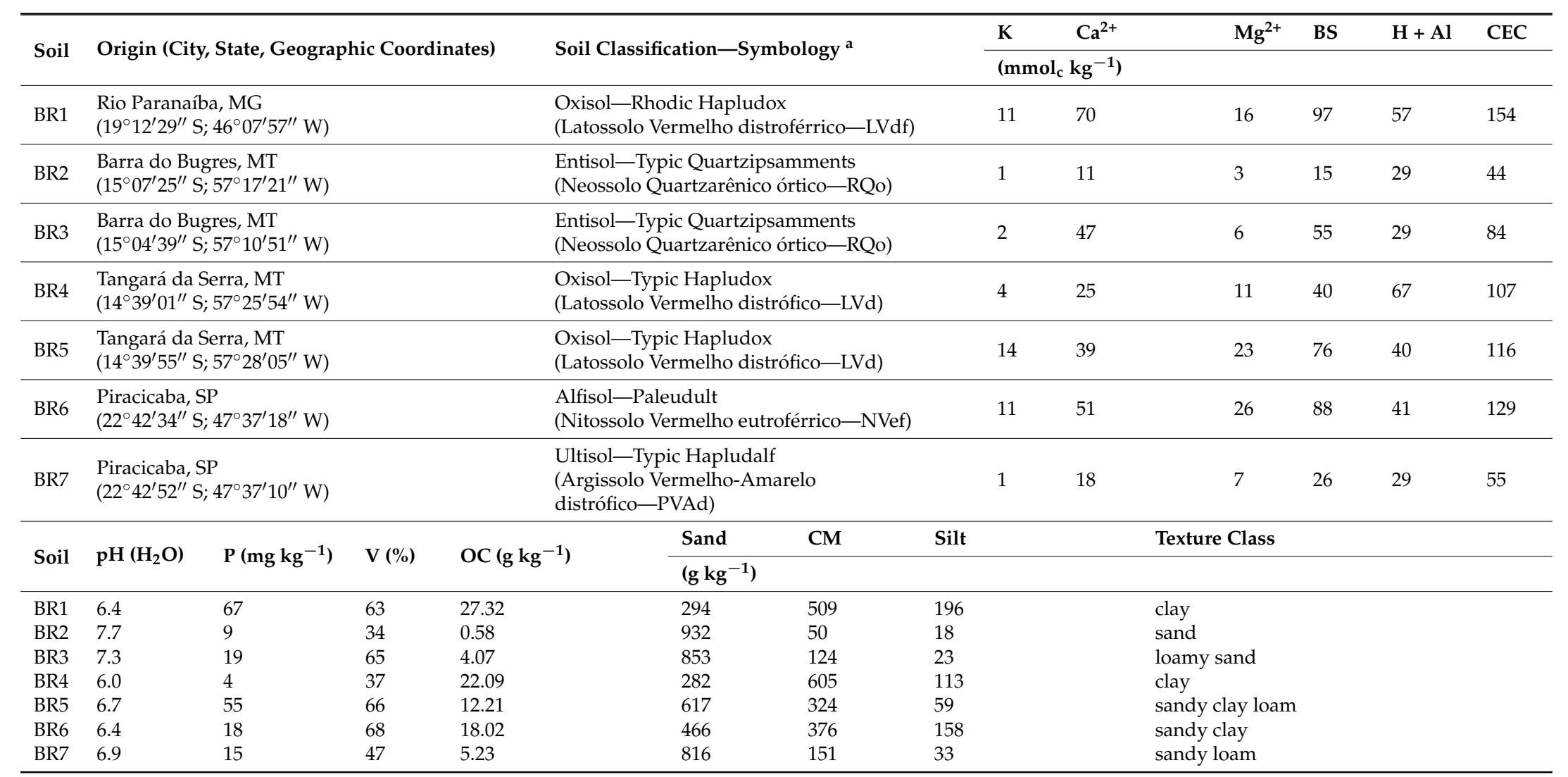

a According to Soil Taxonomy and Brazilian Soil Science Society [16]. BS = base saturation; $\mathrm{CEC}=$ cation exchange capacity; $\mathrm{V}=$ base saturation levels; $\mathrm{OC}=$ organic carbon and CM = clay mineral. Source: Soil Science Department-ESALQ/USP, Piracicaba, SP, Brazil. 


\subsection{Experimental Design}

The methodology was established according to the guidelines of the Organization for Economic Co-operation and Development-312, Leaching in Soil Columns [17]. We used a completely randomized design with three replications, which was then distributed into $2 \times 7 \times 6$ factorial, where the factors were: two types of mesotrione application (alone and in a mixture), seven types of tropical soils cultivated with corn (BR1 to BR7) and six different soil column heights $(0-5,5-10,10-15$, $15-20,20-25$ and $25-30 \mathrm{~cm}$ ).

\subsection{Preparation of Glass Columns Packed with Soil}

Glass columns $50 \mathrm{~cm}$ in height and $5 \mathrm{~cm}$ in diameter were used for each sub-sample of soil (three replications). The lower portion of the columns was filled with quartz wool, followed by a washed quartz sand layer before being dried in an oven at $100^{\circ} \mathrm{C}$. Thereafter the soil samples were packed to a height of $30 \mathrm{~cm}$, weighed to check the reproducibility of the packing process of columns and the dose of mesotrione, with soil samples of BR1 (620.95 g), BR2 (1003.73 g), BR3 (869.85 g), BR4 (670.95 g), BR5 (675.85 g), BR6 (791.00 g) and BR7 (921.74 g).

The soil columns were placed inside a $2.0 \mathrm{~L}$ beaker and were slowly wetted with an upward flow of $\mathrm{CaCl}_{2} 0.01 \mathrm{~mol} \mathrm{~L}^{-1}$ solutions. The columns were flooded for about $30 \mathrm{~min}$. Subsequently, the columns were removed from the beaker and installed on a support and left for $2 \mathrm{~h}$ to drain the $\mathrm{CaCl}_{2}$ solution.

\subsection{Chemicals and Application}

Non-radiolabeled solutions were prepared using analytical standards of mesotrione, S-metolachlor and terbuthylazine of 99.9\%, 98.2\% and 98.8\% purity, respectively (Sigma Aldrich; St. Louis, MO, USA). The ${ }^{14} \mathrm{C}$-mesotrione (cyclohexane-2- ${ }^{14} \mathrm{C}$-mesotrione) had a $98.4 \%$ radiochemical purity and specific activity equal to $3.45 \mathrm{MBq} \mathrm{mg}^{-1}$ (Izotop; Budapest, Hungary). The solutions were prepared containing mesotrione (non-radiolabeled and radiolabeled) with $0.01 \mathrm{~mol} \mathrm{~L}^{-1} \mathrm{CaCl}_{2}$, applied alone and in a mixture, to prepare a $5.0 \mathrm{mg} \mathrm{L}^{-1}\left(1.13 \mathrm{~Bq} \mathrm{~L}^{-1}\right)$ mesotrione, S-metolachlor $\left(41.7 \mathrm{mg} \mathrm{L}^{-1}\right)$ and terbuthylazine $\left(25 \mathrm{mg} \mathrm{L}^{-1}\right)$ solution. Herbicide concentrations were selected to reflect recommended label dosage rates for corn, assuming soil bulk density $=1200 \mathrm{~kg} \mathrm{~m}^{-3}$, incorporation depth $=0.10 \mathrm{~m}$. An aliquot of $200 \mu \mathrm{L}(16.98 \mathrm{kBq}$ radioactivity) of the herbicide solution was applied directly to the soil at the top of each column with an automatic pipette.

\subsection{Leaching Experiments}

After application of the herbicides, a flow of $0.01 \mathrm{~mol} \mathrm{~L}^{-1} \mathrm{CaCl}_{2}$ solution at rate of approximately $8 \mathrm{~mL} \mathrm{~h}^{-1}$ was added for $48 \mathrm{~h}$, resulting in a rain simulation of approximately $200 \mathrm{~mm}$ water depth. After 12, 18, 24, 30, 36, 42 and $48 \mathrm{~h}$ three aliquots of $10 \mathrm{~mL}$ of the leachate solution were collected and added to $10 \mathrm{~mL}$ of solution scintillation liquid (Instagel) for measurement for $15 \mathrm{~min}$ in the liquid spectrometer scintillation (LSS) with Tri-Carb 2910 TR LSA counter (PerkinElmer, Hong Kong, China).

After $48 \mathrm{~h}$ of the herbicide application, the soil material was removed from the columns by injecting air into the top of the column, which was subsequently cut into six equally sized sections $(0-5,5-10,10-15,15-20,20-25$ and 25-30 cm). The soil samples were air-dried, weighed, grinded and homogenized. Three sub-samples $(0.2 \mathrm{~g})$ of each dried soil section were biologically oxidized in an OX500 oxidizer (R. J. Harvey Instrument Corporation, Tappan, NY, USA) for determination of total radioactivity.

The results are expressed as \% of the radioactivity detected in the leachate and in each column soil section, relative to the radioactivity initially applied of mesotrione. The recovery of the experiments was evaluated by the sum of ${ }^{14} \mathrm{C}$-mesotrione percentages found in each soil segment and leachate. To verify the repeatability and analytical sensitivity of the method, samples of oxidized soil and leaching were performed in triplicate. 


\subsection{Statistical Analysis}

Data were subjected to analysis of variance (ANOVA). When significant, the means were compared by Tukey test $(p<0.05)$. Figures were plotted using the Sigma Plot program (version 10.0 for Windows, Systat Software Inc., Point Richmond, CA, USA).

For data related to the leachate in the $\mathrm{CaCl}_{2}$ solution, regression equations were adjusted $(p<0.01)$ by the $\mathrm{F}$ test, using the non-linear model with three parameter Gaussian equation: $\hat{y}=\mathrm{a} \exp (-0.5((x$ $\left.\left.-x_{0}\right) / b\right)^{2}$ ), in which $a$ corresponds to the maximum percentage of leachate mesotrione, $x$ refers to the time of mesotrione determination, $x_{0}$ to the time after application of the maximum percentage of leached mesotrione and $b$ refers to the opening of the peak of the curve.

\section{Results and Discussion}

\subsection{Mass Balance}

The mass recovery (sum of ${ }^{14} \mathrm{C}$-mesotrione percentages found in soil depths and leachate) was 94 to $107 \%$ and 92 to $108 \%$ for the application of the herbicide alone and in mixture, respectively. These values are in accordance with the guidelines of the OECD [17], which states that recovery experiments with radiolabeled substances can range from 90 to $110 \%$.

\subsection{Leaching Mesotrione Alone and in a Mixture}

The triple interaction between the two preparations of mesotrione (alone and in mixture), the seven types of tropical soil and the six soil depths was not significant; indeed, significance was only observed for the double interaction between soil types and depths (Figure 1). The mesotrione preparation in mixture with S-metolachlor and terbuthylazine did not interfere with the leaching when compared with the application of mesotrione alone. This confirmed the results reported by Mendes et al. [18], whereby the sorption coefficients with the same types of soils, showed no differences in mesotrione retention, regardless of application type.

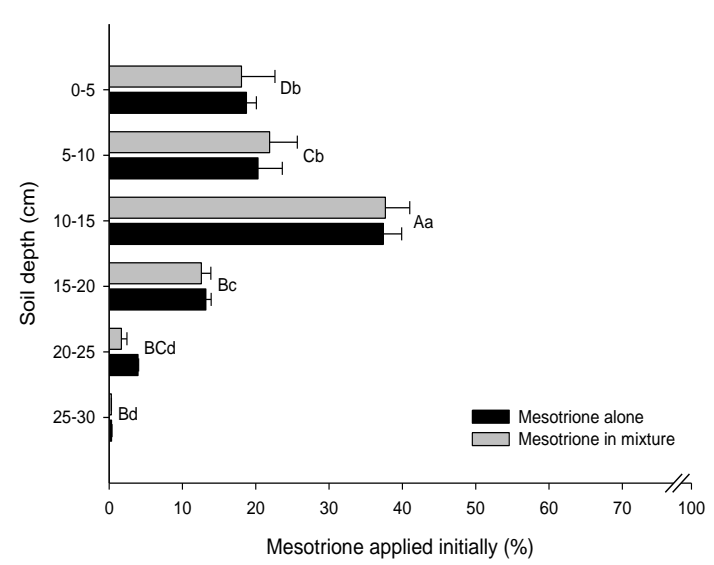

BR1 (a)

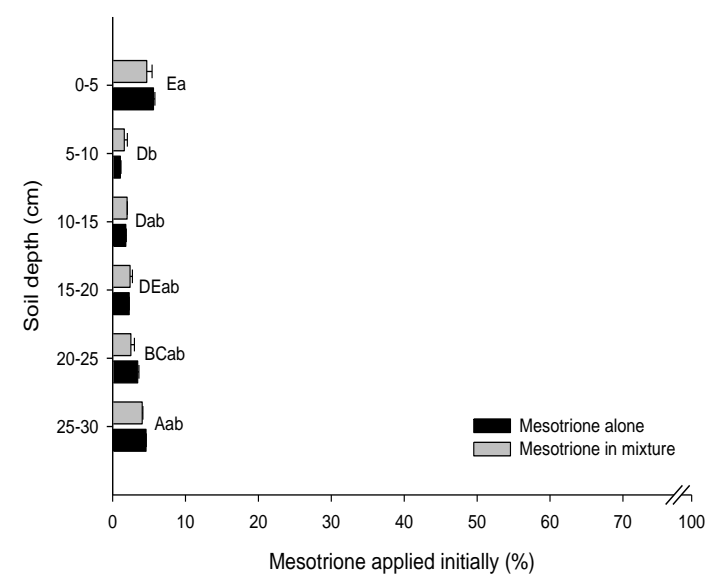

$\mathrm{BR} 2(\mathbf{b})$

Figure 1. Cont. 

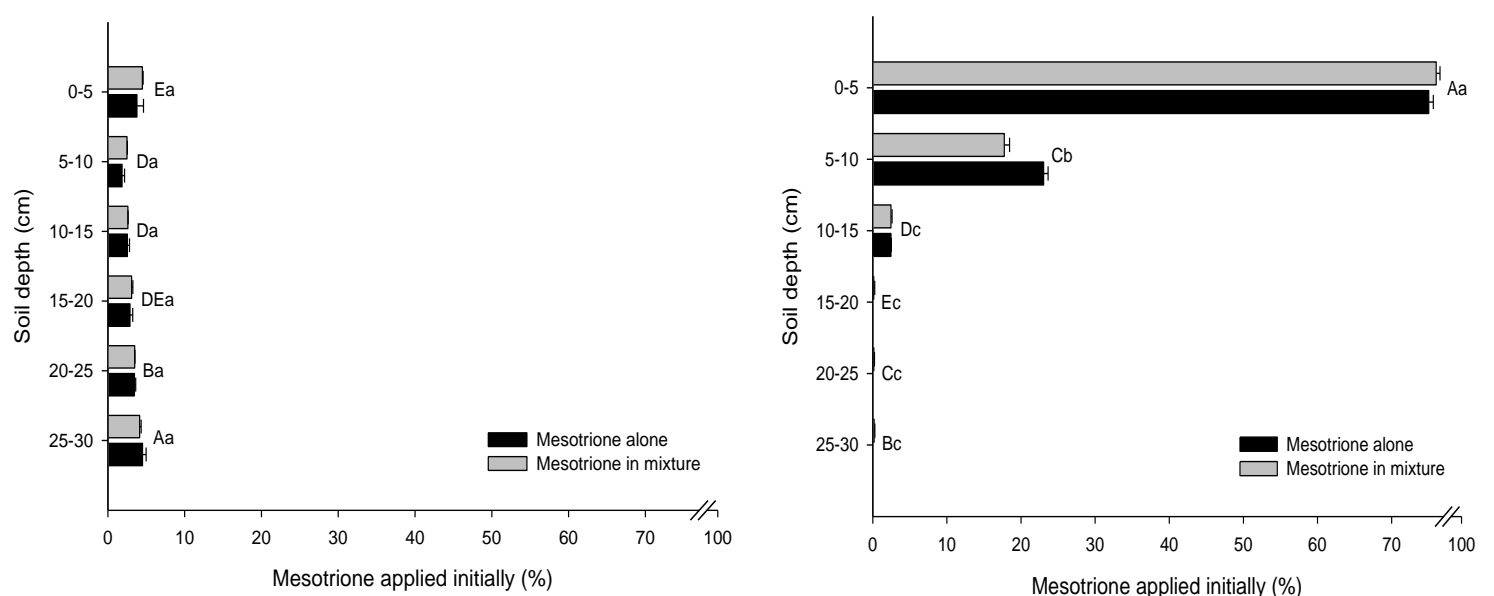

BR3 (c)

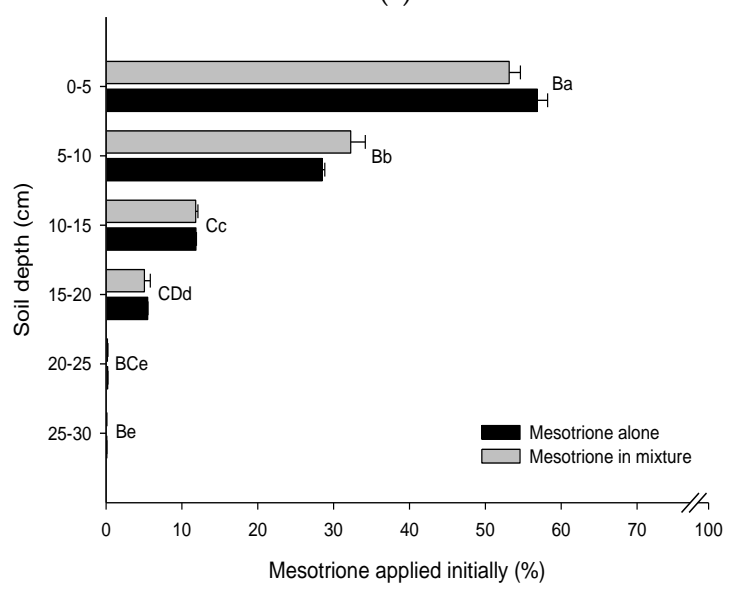

BR4 (d)

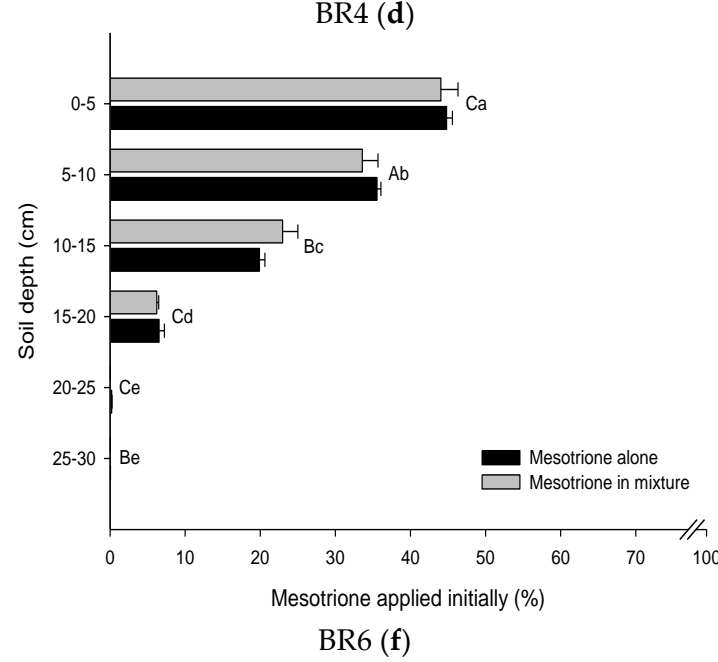

BR5 (e)

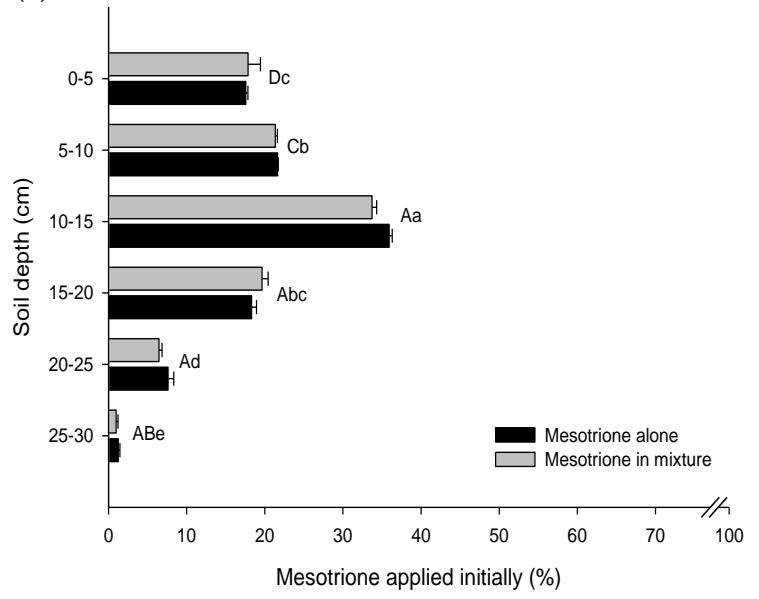

$\mathrm{BR7}(\mathrm{g})$

Figure 1. Percentage ${ }^{14} \mathrm{C}$-mesotrione applied alone and in mixture with S-metolachlor and terbuthylazine in glass columns at different column heights $(0-5,5-10,10-15,15-20,20-25$ and 25-30 cm) and packed with tropical soils, represented by BR1 (a), BR2 (b), BR3 (c), BR4 (d), BR5 (e), BR6 (f) and BR7 (g) with simulation $200 \mathrm{~mm}$ of water for $48 \mathrm{~h}$ after application. The horizontal bars associated with each column represent the standard deviation $( \pm \mathrm{SD})$ of each mean value $(n=3)$. Means followed by the same tiny letter in each depth soil and capital in type soil do not differ by Tukey test $(p<0.05)$. LSD, least significance difference (depth) $=3.2916$, LSD (soil) $=3.4634$ and CV $($ application type $)=1.60 \%, \mathrm{CV}($ soil $)=3.23 \%$ and CV $($ depth $)=12.66 \%$. 
All soils displayed observable sorption and leaching of mesotrione. Independent of application type, the leaching of mesotrione in soil is described in following order as: BR2 $=$ BR3 (very high) > BR7 $>$ BR1 (high) $>$ BR6 $>$ BR5 (moderate) $>$ BR4 (low). Furthermore, the maximum percentage of mesotrione residues was found in the same layer according to the soil studied (Figure 1). These data are consistent with Milan et al. [5] and Marín-Benito et al. [19] that reported mesotrione had high leachabilityin the soil.

In BR1, leaching of mesotrione was distributed between depths but was found in greater amounts $(\sim 37 \%)$ in the intermediate layer of $10-15 \mathrm{~cm}$ (Figure 1a). This was also the case in the same layer of the BR7 sample $(\sim 35 \%)$ (Figure $1 \mathrm{~g})$. This may be because despite having different sorption coefficients $\left(\mathrm{K}_{\mathrm{d}}\right)$, they are both low $\left(\mathrm{BR} 1=\sim 1.05 \mathrm{~kg} \mathrm{~L}^{-1}\right.$ and BR7 $=\sim 0.54 \mathrm{~kg} \mathrm{~L}^{-1}$ ) and the desorption of mesotrione is known to be similar in these soils (approximately 25\%) [18]; therefore, the mesotrione was more available to leach. In other soils, mesotrione residues were distributed differently throughout the column.

The data corroborate with Milan et al. [5], that found the leaching of mesotrione applied in mixture with S-metolachlor and terbuthylazine averaged from 24 to 39\% of that initially applied to columns of 0-40 cm of sandy soil [4] and can be detected at up to $1.8 \mathrm{~m}$ depth silt loam soil, although this was not quantified because of the low-dose application $\left(150 \mathrm{~g} \mathrm{ha}^{-1}\right)$ and rapid dissipation (DT50 = 3-7 days).

In BR4, which is a clay soil with high CM content $\left(605 \mathrm{~g} \mathrm{~kg}^{-1}\right)$, high OC content $\left(22.09 \mathrm{~g} \mathrm{~kg}^{-1}\right)$ and low $\mathrm{pH}(6.0)$ (Table 1$)$, the concentration of mesotrione remained high $(\sim 74 \%)$ in the surface layer $(0-5 \mathrm{~cm})$ (Figure 1d). Moreover, in BR2 (sandy texture) and BR3 (loamy sand texture) with lower CM contents $\left(0.5 \%\right.$ and $12.4 \%$, respectively), lower OC contents ( 0.58 and $4.07 \mathrm{~g} \mathrm{~kg}^{-1}$, respectively) and higher $\mathrm{pH}$ (7.7 and 7.3, respectively) (Table 1 ) leaching was favored at all depths not exceeding 5.6\% in each layer (Figures $1 \mathrm{~b}$ and $1 \mathrm{c}$, respectively). The behavior of these soils can be explained by the small value of $K_{d}\left(<0.24 \mathrm{~kg} \mathrm{~L}^{-1}\right)$ [18], which implies the interaction with the physical and chemical properties of soil on the leaching of mesotrione (Figure 1). Dyson et al. [11] and Shaner et al. [12] found that the sorption of mesotrione was positively correlated with the OC content of the soil.

These results corroborate Pinna et al. [4], who found that mesotrione had a weak affinity with the surface of the soil, which was predominantly negatively charged due to the $\mathrm{pH}$ range of the analyzed soil (5.58 to 6.48) and thus was leached faster. Dyson et al. [11] and Shaner et al. [12] found that the sorption of mesotrione was negatively correlated with $\mathrm{pH}$. However, van der Linden [20] found that the mobility of mesotrione and its two metabolites (MNBA and AMBA) in soil, increased with increasing soil $\mathrm{pH}$.

The data described above can be explained by the fact that mesotrione is a weak acid and has a pKa of 3.1. Thus, its molecular form has the ability to donate protons and form negatively charged ions in higher $\mathrm{pH}$ environments. Passos et al. [21] showed that increasing the $\mathrm{pH}$ value above the $\mathrm{pKa}$ of the herbicide may increase the leaching of sulfentrazone, being a weak acid, as well as mesotrione. In soil pH levels ranging from 6.0 to 7.7 , as is the case in this experiment, the mesotrione molecules are in a dissociated form and thus are more available in the soil solution. Therefore, there is a greater possibility of leaching of mesotrione may contaminate the deeper layers of soil and groundwater even and consequently the surface water, if rains after herbicide application.

Rouchaud et al. [6] reported that mesotrione was leached in a uniform distribution in sandy soil and displayed similar concentrations in all $2 \mathrm{~cm}$ layers, up to a depth of $10 \mathrm{~cm}$ and that a low amount of mesotrione (6-10 $\mu \mathrm{g} \mathrm{kg}^{-1}$ dry soil) reached a depth of $10-15 \mathrm{~cm}$ fastest in clay and sandy texture soils compared with loam soil and sandy loam.

Leaching of mesotrione was similar in BR5 and BR6 soil samples, where it remaining concentrated in the surface layer $(0-5 \mathrm{~cm})$ with quantities of approximately $55 \%$ and $44 \%$, respectively (Figures $1 \mathrm{e}$ and $1 \mathrm{f}$, respectively) but increased with the depth of the soil so that decreased amount of mesotrione and only traces of herbicide $(<0.22 \%)$ reached the deepest layers $(20-30 \mathrm{~cm})$. 
The leaching of herbicides in the soil surface layer (to a depth of $20 \mathrm{~cm}$ ) is of fundamental importance in agronomic practices, as this is the layer that contains the weed seeds with germination potential, so the chemical control would be more effective.

\subsection{Leachate Mesotrione Alone and in a Mixture}

In BR2 and BR3 soil samples, the mesotrione was quantified in the leachate at all sampling times as $87.41 \%$ and $81.40 \%$, respectively, of the initially applied mesotrione preparation alone (Figure $2 \mathrm{a}$ ). This fact corroborates the small amount of mesotrione found at different depths in the BR2 and BR3 samples, which is justified by the texture (sand and loamy sand, respectively) and $\mathrm{pH}$ (7.7 and 7.3, respectively) of these soils (Table 1). In the same soils, the mesotrione preparation with S-metolachlor and terbuthylazine displayed a total of $85.69 \%$ and $80.56 \%$, respectively, at every sampling time, demonstrating that the combination of chemicals does not influence the leaching of mesotrione (Figure 2b). Marín-Benito et al. [19] also detected and quantified, only 19 days after application, mesotrione alone in leachate at $1 \mathrm{~m}$ depth in lysimeters containing clay loam soil, with 32.3 to $43.8 \% \mathrm{CM}$, 1.38 to $0.24 \%$ OC and 6.68 to $07.87 \mathrm{pH}$ in an irrigated maize monoculture system in Toulouse (France).
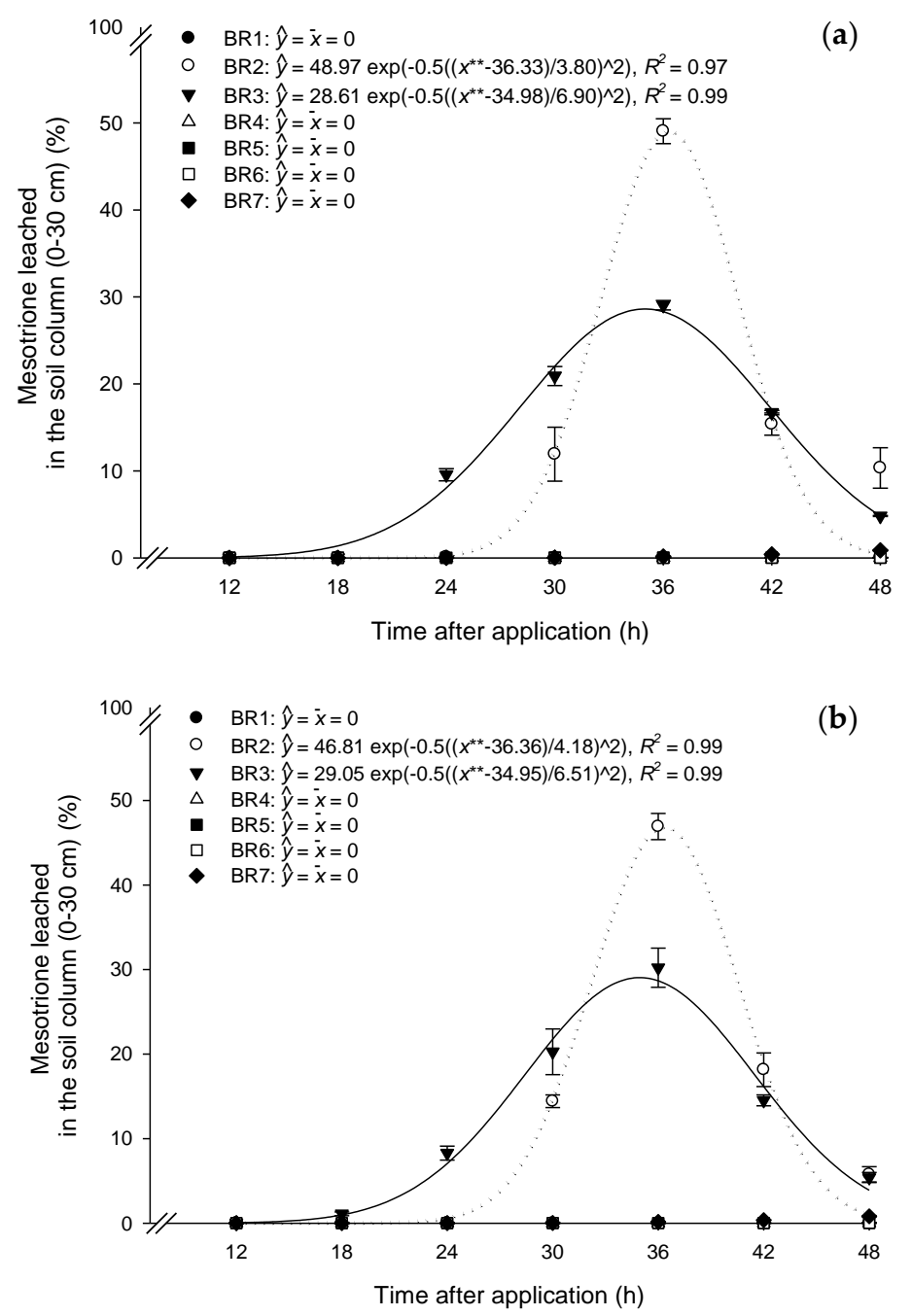

Figure 2. Percentage of leached ${ }^{14} \mathrm{C}$-mesotrione applied alone (a) and in mixture with S-metolachlor plus terbuthylazine $(\mathbf{b})$ in glass columns $(0-30 \mathrm{~cm})$ packed with tropical soils, represented by BR1, BR2, BR3, BR4, BR5, BR6 and BR7 with simulation $200 \mathrm{~mm}$ of water and collected at 12, 18, 24, 30, 36, 42 and $48 \mathrm{~h}$ after application. The vertical bars associated with each column represent the standard deviation $( \pm \mathrm{SD})$ of each mean value $(n=3) .{ }^{* *} p<0.01$ by the $F$ test. 
In other soils, in both mesotrione preparations, the value of herbicide found in the leachate was minimal $(<1.45 \%)$ and showed similar behavior (Figure $2 \mathrm{a}, \mathrm{b})$. However, higher concentrations of mesotrione in these soils were reported at different depths, as described above. According to Rouchaud et al. [6], the mesotrione mainly remains in the topsoil $(0-10 \mathrm{~cm})$. This low mobility and penetration depth, in conjunction with mesotrione degradation in soil, explains why there is no movement of the mesotrione to the deeper soil layers.

In BR2 soil, the maximum amount of mesotrione found in the leachate was $48.97 \%$ and $46.81 \%$ $36.3 \mathrm{~h}$ after application of the herbicide alone and in mixture with S-metolachlor and terbuthylazine, respectively (Figures 2a and 2b, respectively). In BR3, the maximum amount of mesotrione found in the leachate was $28.61 \%$ and $29.05 \% 35.0 \mathrm{~h}$ after application of the herbicide alone and in mixture, respectively (Figures $2 \mathrm{a}$ and $2 \mathrm{~b}$, respectively). Given the above, we understand that the type of mesotrione application did not interfere in the behavior in the leachate.

Therefore, depending on the type of cultivatable soil with corn, the mesotrione can be easily leached and cause environmental damage as a result of its mobility in the soil profile. Alferness and Wiebe [7] detected the presence of mesotrione and two metabolites (4-methylsulfonyl-2-nitrobenzoic acid-MNBA and 2-amino-4-methylsulphonylbenzoic acid-AMBA) in groundwater, surface seawater and rivers.

\section{Conclusions}

The application type of mesotrione alone and in a mixture with S-metolachlor and terbuthylazine does not influence the leaching of this herbicide. Leaching of mesotrione ranged from low (up $15 \mathrm{~cm}$ ) to very high (up $30 \mathrm{~cm}$ and leachate) in the evaluated tropical soils and thus can present potential groundwater contamination risks and therefore surface water in areas producing corn. Thus, mesotrione application without the prior knowledge of the soil physical and chemical properties can result in inefficient weed control on field condition due to high leaching potentials.

Acknowledgments: The authors would like to thank the São Paulo Research Foundation (FAPESP) (2013/25399-3) for the financial support.

Author Contributions: K.F.M. carried out the studies, statistical analysis and wrote the paper. V.L.T. was adviser of the first author, was responsible for the training and participated in the definition of the methodology. M.R.d.R. carried out the wrote and revised the paper. K.A.S. carried out the wrote the paper and participated in the definition of the methodology.

Conflicts of Interest: The authors declare no conflict of interest.

\section{References}

1. Cheng, H.H. Pesticide in Soil Environment: Processes, Impacts and Modeling; Soil Science Society of America: Madison, WI, USA, 1990; p. 511.

2. Brady, N.C.; Weil, R.R. Soil and Chemical Pollution. In The Nature and Properties of Soils; Weil, R., Brady, N., Eds.; Pearson Education: Berkeley, CA, USA, 2016; pp. 879-935.

3. Nurse, R.E.; Hamill, A.S.; Swanton, C.J.; Tardif, F.J.; Sikkema, P.H. Weed control and yield response to mesotrione in maize (Zea mays). Crop Prot. 2010, 29, 652-657. [CrossRef]

4. Pinna, M.V.; Roggero, P.P.; Seddaiu, G.; Pusino, A. Soil sorption and leaching of active ingredients of Lumax ${ }^{\circledR}$ under mineral or organic fertilization. Chemosphere 2014, 111, 372-378. [CrossRef] [PubMed]

5. Milan, M.; Ferrero, A.; Fogliatto, S.; Piano, S.; Vidotto, F. Leaching of S-metolachlor, terbuthylazine, desethyl-terbuthylazine, mesotrione, flufenacet, isoxaflutole, and diketonitrile in field lysimeters as affected by the time elapsed between spraying and first leaching event. J. Environ. Sci. Health Part B 2015, 50, 851-861. [CrossRef] [PubMed]

6. Rouchaud, J.; Neus, O.; Eelen, H.; Bulcke, R. Mobility and adsorption of the triketone herbicide mesotrione in the soil of corn crops. Toxicol. Environ. Chem. 2001, 79, 211-222. [CrossRef] 
7. Alferness, P.; Wiebe, L. Determination of mesotrione residues and metabolites in crops, soil, and water by liquid chromatography with fluorescence detection. J. Agric. Food Chem. 2002, 50, 3926-3934. [CrossRef] [PubMed]

8. Mastichiadis, C.; Christofidis, I.; Koupparis, M.A.; Willetts, C.; Kakabakos, S.E. Solid-phase fluoroimmunoassay for the determination of mesotrione-A novel triketone herbicide-In water with direct measurement of the fluorescence onto the solid support. Analyst 2003, 128, 404-410. [CrossRef] [PubMed]

9. Freitas, L.G.; Götz, C.W.; Ruff, M.; Singer, H.P.; Müller, S.R. Quantification of the new triketone herbicides, sulcotrione and mesotrione, and other important herbicides and metabolites, at the ng/l level in surface waters using liquid chromatography-tandem mass spectrometry. J. Chromatogr. A 2004, 1028, 277-286. [CrossRef] [PubMed]

10. Barchanska, H.; Rusek, M.; Szatkowska, A. New procedures for simultaneous determination of mesotrione and atrazine in water and soil. Comparison of the degradation processes of mesotrione and atrazine. Environ. Monit. Assess. 2012, 184, 321-334. [CrossRef] [PubMed]

11. Dyson, J.S.; Beulke, S.; Brown, C.D.; Lane, M.C.G. Adsorption and degradation of the weak acid mesotrione in soil and environmental fate implications. J. Environ. Qual. 2002, 31, 613-618. [CrossRef] [PubMed]

12. Shaner, D.; Brunk, G.; Nissen, S.; Westra, P.; Chen, W. Role of soil sorption and microbial degradation on dissipation of mesotrione in plant-available soil water. J. Environ. Qual. 2012, 41, 170-178. [CrossRef] [PubMed]

13. Alekseeva, T.; Kolyagin, Y.; Sancelme, M.; Besse-Hoggan, P. Effect of soil properties on pure and formulated mesotrione adsorption onto vertisol (Limagne plane, Puy-de-Dôme, France). Chemosphere 2014, 111, 177-183. [CrossRef] [PubMed]

14. Singh, B.K.; Walker, A.; Wright, D.J. Degradation of chlorpyrifos, fenamiphos, and chlorothalonil alone and in combination and their effects on soil microbial activity. Environ. Toxicol. Chem. 2002, 21, 2600-2605. [CrossRef] [PubMed]

15. Swarcewicz, M.K.; Gregorczyk, A. The effects of pesticide mixtures on degradation of pendimethalin in soils. Environ. Monit. Assess. 2012, 184, 3077-3084. [CrossRef] [PubMed]

16. Empresa Brasileira de Pesquisa Agropecuária. Sistema Brasileiro de Classificação de Solos, 3rd ed.; Embrapa Solos: Brasília, Brazil, 2013.

17. Organization for Economic Co-operation and Development (OECD). OECD Guidelines for Testing of Chemicals; Test No. 312: Leaching in Soil Columns; Organization for Economic Co-operation and Development (OECD): Paris, France, 2004.

18. Mendes, K.F.; Reis, M.R.; Inoue, M.H.; Pimpinato, R.F.; Tornisielo, V.L. Sorption and desorption of mesotrione alone and mixed with S-metolachlor + terbuthylazine in Brazilian soils. Geoderma 2016, 280, 22-28. [CrossRef]

19. Marín-Benito, J.M.; Pot, V.; Alletto, L.; Mamy, L.; Bedos, C.; Barriuso, E.; Benoit, P. Comparison of three pesticide fate models with respect to the leaching of two herbicides under field conditions in an irrigated maize cropping system. Sci. Total Environ. 2014, 499, 533-545. [CrossRef] [PubMed]

20. Van der Linden, A.M.A.; Tiktak, A.; Boesten, J.J.T.I.; Leijnse, A. Influence of pH-dependent sorption and transformation on simulated pesticide leaching. Sci. Total Environ. 2009, 407, 3415-3420. [CrossRef] [PubMed]

21. Passos, A.B.R.J.; Freitas, M.A.M.; Gonçalves, V.A.; Silva, G.S.; da Silva, A.A.; Queiroz, M.E.L.R.; Lima, C.F.; Silva, D.V. Leaching of sulfentrazone in soils of reforestation in Brazil. Environ. Earth Sci. 2015, 74, 1211-1215. [CrossRef]

(C) 2017 by the authors. Licensee MDPI, Basel, Switzerland. This article is an open access article distributed under the terms and conditions of the Creative Commons Attribution (CC BY) license (http:/ / creativecommons.org/licenses/by/4.0/). 